\title{
COMPOSIÇÃO CENTESIMAL E CONTEÚDO DE AMINOÁCIDOS, ÁCIDOS GRAXOS E MINERAIS DE SEIS CULTIVARES DE SOJA DESTINADAS À ALIMENTAÇÃO HUMANA ${ }^{1}$
}

\author{
CLAUDIA REGINA VIEIRA ${ }^{2}$, LAIR CHAVES CABRAL ${ }^{3}$ e ALLAN CESAR OLIVEIRA DE PAULA ${ }^{4}$
}

RESUMO - Seis cultivares de soja (Glycine max L. Merrill): IAS-4, EMBRAPA-4, Davis, BR-16, Iguaçu e IAS-5, destinadas à alimentação humana, foram caracterizadas quanto à composição centesimal, conteúdo de aminoácidos, ácidos graxos e minerais. Os teores de fibra, proteína e óleo variaram significativamente nas amostras analisadas, enquanto que os teores de cinzas não apresentaram diferenças significativas. Com relação aos teores de minerais, o potássio foi o que obteve o maior valor, $1.824,02 \mathrm{mg} / 100 \mathrm{~g}$ para a cultivar Iguaçu, ficando a EMBRAPA-4 com o maior teor de cálcio, $313,93 \mathrm{mg} / 100 \mathrm{~g}$. Para a composição em ácidos graxos, notou-se que a cultivar IAS-5 apresentou o maior teor de insaturados, $87,45 \%$, enquanto que a Davis, o menor, $83,93 \%$. A cultivar EMBRAPA-4 apresentou um teor de ácido oléico maior e de linoléico e linolênico bem menores que as demais cultivares estudadas, $39,93 \%, 42,46 \%$ e 4,64\%, respectivamente. Os demais ácidos graxos estão de acordo com os valores encontrados na literatura no tocante a óleo de soja. Todas as cultivares estudadas apresentaram excelente balanço em aminoácidos essenciais (AAE). Os teores de cada AAE foram superiores aos da proteína padrão estabelecido pela $\mathrm{FAO} / \mathrm{WHO}$, com valor total de AAE variando de 39,5 a 45,0 g/100 g de proteína.

Termos para indexação: Glycine max, caracterização química, proteína, óleo, cinzas.

\section{PROXIMATE COMPOSITION AND AMINO ACID, FATTY ACID AND MINERAL CONTENTS OF SIX SOYBEAN CULTIVARS FOR HUMAN CONSUMPTION}

\begin{abstract}
Six soybean cultivars (Glycine max L. Merrill): IAS-4, EMBRAPA-4, Davis, BR-16, Iguaçu and IAS-5, for human consumption were characterized regarding their proximate composition and amino acid, fatty acids and mineral contents. Significant differences were observed among these varieties concerning their contents of protein, oil and fiber. However, their ash content did not show significant differences. Regarding the mineral composition, the cultivars Iguaçu and EMBRAPA-4 presented, respectively, the highest levels of potassium $(1824.02 \mathrm{mg} / 100 \mathrm{~g})$ and calcium $(313.93 \mathrm{mg} / 100 \mathrm{~g})$. It was observed that the cultivar IAS-5 presented the highest level of unsaturated fatty acids $(87.45 \%)$, while the cultivar Davis, the lowest one $(83.93 \%)$. The cultivar EMBRAPA-4 presented the highest level of oleic acid and levels of linoleic and linolenic acids lower than the ones obtained for the other studied cultivars (39.93\%, $42.46 \%$ and $4.64 \%$, respectively). The results obtained for the other fatty acids levels are in agreement with the ones reported for soybean oil in the literature. All six cultivars studied presented an excellent balance of essential amino acids (EAA). The contents of each EAA were higher than those presented in the reference pattern established by $\mathrm{FAO} / \mathrm{WHO}$ with the total EAA ranging from 39.5 to $45.0 \mathrm{~g} / 100 \mathrm{~g}$ of protein.
\end{abstract}

Index terms: Glycine max, chemical characterization, protein, oil, ash.

\footnotetext{
${ }^{1}$ Aceito para publicação em 16 de outubro de 1998.

${ }^{2}$ Química, Embrapa-Centro Nacional de Pesquisa de Tecnologia Agroindustrial de Alimentos (CTAA), Av. das Américas, 29.501, CEP 23030-470 Guaratiba, Rio de Janeiro, RJ. E-mail: crvieira@ctaa.embrapa.br

${ }^{3}$ Químico, Ph.D., Embrapa-CTAA.

${ }^{4}$ Químico, M.Sc., Embrapa-CTAA.
}

\section{INTRODUÇÃO}

O Brasil alcançou rapidamente a posição de segundo produtor mundial de soja, com uma produção em torno de 26 milhões de toneladas na safra 1995/96. Acredita-se que nos próximos anos have- 
rá um aumento contínuo da produção, dada a crescente importância que a soja passou a ocupar na economia brasileira, sobretudo por ser uma valiosa fonte de proteínas e óleo para a alimentação humana (Agroanalysis, 1996).

A composição química da soja pode variar com as condições climáticas, tipo de solo, localização geográfica, variedades e práticas agronômicas, entre outros fatores (Horan, 1974).

As frações de proteína e óleo da soja compreendem aproximadamente $60 \%$ do total do peso seco da semente. Os grãos maduros contêm cerca de $40,7 \%$ de proteína, $22,7 \%$ de óleo, $10,9 \%$ de açúcares totais, $6,7 \%$ de fibra e cerca de $5,8 \%$ de cinzas e $30,8 \%$ de carboidratos, em base seca (Costa et al., 1973/74).

Tango et al. (1983), estudando o teor e as características do óleo de diversas cultivares de soja provenientes de quatro regiões brasileiras, verificaram que o conteúdo de óleo e a composição em ácidos graxos variaram significativamente em função da cultivar e do local de plantio.

Costa et al. (1973/74) estudaram a composição química de sete cultivares de soja plantadas no Estado de São Paulo e não encontraram diferenças estatísticas no conteúdo de aminoácidos das amostras analisadas.

Com relação ao conteúdo de minerais na soja, López-Andreu et al. (1985) verificaram pouca diferença entre algumas cultivares plantadas nas mesmas condições de cultivo. De acordo com os resultados, os minerais mais abundantes foram $\mathrm{K}, \mathrm{P}, \mathrm{Mg}$ e Ca, com 1960,0, 629,0, 269,5 e 188,5 mg/100 g da amostra, respectivamente.

Liu et al. (1995), estudando cultivares de soja visando identificar as mais adequadas à alimentação humana, principalmente no que diz respeito a leite e Tofu, concluíram que elas deveriam possuir as seguintes características: grãos de tamanho grande, cor da casca branca ou amarela, hilo claro, alto teor de proteína e médio teor de óleo.

O trabalho teve por objetivo avaliar seis cultivares de soja destinadas à alimentação humana, sob o aspecto da composição centesimal do grão, conteúdo de ácidos graxos, aminoácidos e sais minerais.

\section{MATERIAL E MÉTODOS}

As cultivares de soja (Glycine max L. Merrill) utilizadas foram IAS-4, BR-16 e Iguaçu, provenientes do Rio Grande do Sul, EMBRAPA-4 e Davis, do Paraná e IAS-5, do Estado de São Paulo. Todas foram previamente selecionadas dentre as principais cultivares plantadas no Brasil, de acordo com suas características físicas recomendadas para alimentação humana, tais como cor clara da casca e do hilo e peso elevado de 100 sementes (>15 g/100 sementes).

As amostras foram previamente limpadas e selecionadas por tamanho, transformadas em farinhas e então acondicionadas em recipientes de vidro, hermeticamente fechados, à temperatura ambiente até sua utilização.

Os teores de umidade, proteína, óleo e cinzas foram determinados segundo a metodologia recomendada pela Association of Official Analytical Chemists (1984) e o de fibra, segundo o Instituto Adolfo Lutz (1985).

A análise de minerais foi realizada segundo a metodologia recomendada pela Association of Official Analytical Chemists (1984), que consiste na digestão nitroperclórica da amostra. A medida dos minerais foi realizada com espectrômetro de emissão óptica com excitação ICP, marca Spectro Analytical Instruments.

A proteína foi caracterizada quanto a sua composição em aminoácidos, segundo a metodologia recomendada pela Association of Official Analytical Chemists (1984), por hidrólise das proteínas em $\mathrm{HCl}$ concentrado, sob refluxo das amostras desengorduradas por 24 horas. A quantificação dos aminoácidos foi realizada em um cromatógrafo líquido de alta eficiência (CLAE), marca Hewlett Packard Mod. 1090 M.

O óleo extraído de cada cultivar foi caracterizado por cromatografia gasosa quanto à sua composição em ácidos graxos. Para tanto, os ésteres metílicos foram preparados de acordo com a técnica de Hartman \& Lago (1973) e analisados por cromatografia gasosa de alta resolução, utilizando-se um equipamento marca HP-5890 série II, com coluna capilar de sílica fundida, de $25 \mathrm{~m} \mathrm{x} \mathrm{0,2} \mathrm{mm}$ x $0,33 \mu \mathrm{m}$ de FFAP. A temperatura da coluna foi de $210^{\circ} \mathrm{C}$, do injetor, $250^{\circ} \mathrm{C}$ e do detector, $280^{\circ} \mathrm{C}$. A identificação dos ácidos graxos foi realizada por comparação com padrões analisados nas mesmas condições.

\section{RESULTADOS E DISCUSSÃO}

Os dados referentes à composição centesimal das cultivares estudadas encontram-se na Tabela 1.

Como pode ser observado, os teores de óleo, proteína e fibra das seis cultivares de soja estudadas 
diferiram significativamente, enquanto os de cinzas não apresentaram diferenças estatísticas. Observouse que existe correlação negativa entre os conteúdos de óleo e proteína $(\mathrm{r}=-0,47)$. Resultados semelhantes foram obtidos por Costa et al. (1973/74), Sakla et al. (1988) e Mandarino et al. (1992). Com exceção da cultivar EMBRAPA-4, a soma desses componentes manteve-se dentro dos limites de $62 \pm 0,5 \%$. Os teores de carboidratos não apresentaram variação expressiva entre as cultivares, com exceção da EMBRAPA-4, que apresentou um valor relativamente baixo em relação às demais. As porcentagens de óleo variaram de $22,24 \%$ a $23,80 \%$, proteína, de $38,55 \%$ a $41,95 \%$, fibra, de $5,24 \%$ a $6,38 \%$, cinzas, de $5,24 \%$ a $5,57 \%$ e carboidratos, de $29,81 \%$ a $33,33 \%$, sendo o conteúdo médio desses nutrientes igual a $23,04 \%, 39,52 \%, 5,75 \%, 5,41 \%$ e $32,01 \%$, respectivamente. Os resultados obtidos no tocante à composição centesimal das seis cultivares de soja situam-se dentro da faixa encontrada por Turatti et al. (1979), em estudo envolvendo 25 cultivares comerciais.

Na Tabela 2, estão os resultados referentes à composição em minerais das diferentes cultivares estudadas.

$\mathrm{O} \mathrm{K}$ foi o mineral mais abundante entre todas as cultivares, com um teor máximo de 1824,02 mg/100 g para a cultivar Iguaçu, e mínimo de $1.567,05 \mathrm{mg} / 100 \mathrm{~g}$ para a cultivar EMBRAPA-4
Os conteúdos de $\mathrm{P}, \mathrm{Ca}$ e $\mathrm{Mg}$ variaram de 454,71 a $503,84 \mathrm{mg} / 100 \mathrm{~g}$, de 170,19 a $313,93 \mathrm{mg} / 100 \mathrm{~g}$ e de 214,36 a $259,97 \mathrm{mg} / 100 \mathrm{~g}$, respectivamente. As concentrações de $\mathrm{Fe}, \mathrm{Mn}$ e $\mathrm{Na}$, apresentaram variação entre 13,39 e 19,12 mg/100 g, 1,75 e $2,79 \mathrm{mg} / 100 \mathrm{~g}$, e 11,73 e $12,08 \mathrm{mg} / 100 \mathrm{~g}$, respectivamente. A elevada variação nos teores de minerais entre as cultivares estudadas pode estar relacionada com as condições de cultivo, clima, solo e adubação (Smith \& Circle,1972; Costa et al., 1973/74).

Com exceção do $\mathrm{P}$, os demais minerais presentes nas cultivares estudadas apresentaram teores semelhantes aos relatados por Mandarino et al. (1992). Os mesmos autores encontraram teores mais elevados quanto ao $\mathrm{P}$ em comparação com os resultados obtidos no presente estudo.

Ologhobo \& Fetuga (1984) obtiveram resultados superiores para $\mathrm{P}, \mathrm{K}, \mathrm{Na}$ e $\mathrm{Mn}$, semelhantes para $\mathrm{Ca}$ e $\mathrm{Mg}$ e inferiores para $\mathrm{Fe}$.

Segundo Amaral (1981) e Oliveira (1981), a soja é uma importante fonte de minerais como $\mathrm{K}, \mathrm{Fe}$ e $\mathrm{Ca}$, com destaque para o elevadíssimo teor de $\mathrm{K}$, cerca de $2 \%$, o qual concorre para a manutenção do equilíbrio eletrolítico do tecido. Outros investigadores, no entanto, sugerem que os minerais podem interagir com substâncias como ácido fítico, fibra e polifenóis, dificultando a sua biodisponibilidade (Jaffe, 1981; Liener, 1981; Erdman \& Fordyce, 1989; Mohamed et al., 1991).

TABELA 1. Composição química das cultivares de soja estudadas (base seca) ${ }^{\mathbf{1}}$.

\begin{tabular}{lccccc}
\hline Cultivares & $\begin{array}{c}\text { Óleo } \\
(\%)\end{array}$ & $\begin{array}{c}\text { Proteína } \\
(\%)\end{array}$ & $\begin{array}{c}\text { Fibra } \\
(\%)\end{array}$ & $\begin{array}{c}\text { Cinzas } \\
(\%)\end{array}$ & $\begin{array}{c}\text { Carboidratos } \\
\text { totais }^{2}(\%)\end{array}$ \\
\hline IAS-4 & $23,24 \mathrm{ab}$ & $39,30 \mathrm{ab}$ & $5,24 \mathrm{~d}$ & 5,34 & 32,12 \\
EMBRAPA-4 & $22,93 \mathrm{bc}$ & $41,95 \mathrm{a}$ & $5,90 \mathrm{bc}$ & 5,31 & 29,81 \\
Davis & $23,80 \mathrm{a}$ & $38,55 \mathrm{bc}$ & $5,47 \mathrm{~cd}$ & 5,57 & 32,08 \\
BR-16 & $22,87 \mathrm{~cd}$ & $38,56 \mathrm{c}$ & $5,85 \mathrm{~b}$ & 5,24 & 33,33 \\
Iguaçu & $23,33 \mathrm{ab}$ & $38,57 \mathrm{bc}$ & $5,66 \mathrm{bc}$ & 5,56 & 32,54 \\
IAS-5 & $22,24 \mathrm{~d}$ & $40,17 \mathrm{ab}$ & $6,38 \mathrm{a}$ & 5,43 & 32,16 \\
\hline Média & 23,04 & 39,52 & 5,75 & 5,41 & 32,01 \\
Quadrado médio & 1,17 & 5,66 & 0,37 & $0,08^{\mathrm{ns}}$ & - \\
\hline
\end{tabular}

1 Médias na coluna seguidas de letras diferentes diferem entre si $(\mathrm{P}<0,05)$, pelo teste de Tukey.

${ }^{2}$ Calculados por diferença: Carboidratos $=100-($ proteína + óleo + cinza $)$ 
A composição em aminoácidos das seis cultivares de soja está apresentada na Tabela 3.

Como pode ser observado, não houve diferença substancial nos teores de aminoácidos das cultivares. Os valores encontrados são semelhantes aos re- latados por Eldridge (1983), Ologhobo \& Fetuga (1984), Vasconcelos et al. (1997) e Zarcadas et al. (1997).

Os aminoácidos mais abundantes foram o ácido glutâmico e o ácido aspártico, com um conteúdo de

TABELA 2. Composição de minerais das cultivares de soja estudadas.

\begin{tabular}{lccccccc}
\hline \multirow{2}{*}{ Cultivares } & \multicolumn{7}{c}{ Minerais $(\mathrm{mg} / 100 \mathrm{~g}$ amostra seca) } \\
\cline { 2 - 7 } & Manganês & Fósforo & Potássio & Sódio & Cálcio & Ferro & Magnésio \\
\hline IAS-4 & 2,50 & 468,28 & $1.744,66$ & 12,08 & 170,19 & 15,53 & 231,02 \\
EMBRAPA-4 & 2,79 & 454,71 & $1.567,05$ & 11,99 & 313,93 & 13,39 & 259,97 \\
Davis & 2,24 & 503,84 & $1.821,09$ & 11,73 & 217,62 & 15,71 & 237,73 \\
BR-16 & 2,47 & 454,82 & $1.662,28$ & 11,88 & 209,55 & 19,12 & 214,36 \\
Iguaçu & 2,71 & 456,30 & $1.824,02$ & 11,92 & 243,83 & 16,36 & 228,53 \\
IAS-5 & 1,75 & 498,44 & $1.685,84$ & 11,88 & 236,24 & 18,57 & 222,53 \\
\hline
\end{tabular}

TABELA 3. Composição em aminoácidos das proteínas das cultivares de soja estudadas e do padrão da FAO (1985).

\begin{tabular}{|c|c|c|c|c|c|c|c|c|c|}
\hline \multirow[t]{2}{*}{ Aminoácidos } & \multicolumn{3}{|c|}{ FAO $(\mathrm{g} / 100 \mathrm{~g}$ de proteína $)$} & \multicolumn{6}{|c|}{ Cultivares $(\mathrm{g} / 100 \mathrm{~g}$ de proteína) } \\
\hline & $\begin{array}{c}2-5 \\
\text { anos }\end{array}$ & $\begin{array}{c}10-12 \\
\text { anos }\end{array}$ & Adulto & IAS-4 & EMBRAPA-4 & Davis & BR-16 & Iguaçu & IAS-5 \\
\hline \multicolumn{10}{|l|}{ Essenciais } \\
\hline Histidina & 1,9 & 1,9 & 1,6 & 1,9 & 1,8 & 1,9 & 2,0 & 2,4 & 2,4 \\
\hline Isoleucina & 2,8 & 2,8 & 1,3 & 4,1 & 3,5 & 3,8 & 3,7 & 4,1 & 4,0 \\
\hline Leucina & 6,6 & 4,4 & 1,9 & 7,8 & 7,1 & 7,4 & 7,3 & 7,8 & 7,9 \\
\hline Lisina & 5,8 & 4,4 & 1,6 & 6,4 & 5,6 & 5,8 & 6,0 & 6,8 & 6,9 \\
\hline Metionina & - & - & - & 1,3 & 1,2 & 1,3 & 1,3 & 1,4 & 1,3 \\
\hline Cisteína & - & - & - & 2,5 & 2,0 & 2,5 & 2,2 & 2,4 & 2,3 \\
\hline Sulfurados (Met + Cys) & 2,5 & 2,2 & 1,7 & 3,8 & 3,2 & 3,8 & 3,5 & 3,8 & 3,6 \\
\hline Fenilalanina & - & - & - & 6,2 & 6,1 & 6,2 & 6,0 & 6,5 & 6,7 \\
\hline Tirosina & - & - & - & 3,2 & 3,0 & 3,3 & 3,1 & 3,4 & 3,5 \\
\hline Aromáticos (Phe + Tyr) & 6,3 & 2,2 & 1,9 & 9,4 & 9,1 & 9,5 & 9,1 & 9,9 & 10,2 \\
\hline Treonina & 3,4 & 2,8 & 0,9 & 3,9 & 3,5 & 3,9 & 3,8 & 4,0 & 4,1 \\
\hline Triptofano & 1,1 & 0,9 & 0,5 & 1,7 & 1,6 & 1,5 & 1,6 & 1,5 & 1,5 \\
\hline Valina & 3,5 & 2,5 & 1,3 & 4,1 & 4,1 & 4,3 & 4,1 & 4,6 & 4,4 \\
\hline Total $\mathrm{AAE}^{1}$ & 33,9 & 24,1 & 12,7 & 43,1 & 39,5 & 41,9 & 41,1 & 44,9 & 45,0 \\
\hline \multicolumn{10}{|l|}{ Não essenciais } \\
\hline Arginina & - & - & - & 7,4 & 7,4 & 6,8 & 6,8 & 7,3 & 7,2 \\
\hline Alanina & - & - & - & 4,3 & 3,8 & 4,0 & 3,9 & 4,2 & 4,4 \\
\hline Ácido aspártico & - & - & - & 12,8 & 13,1 & 14,2 & 13,7 & 14,6 & 14,7 \\
\hline Ácido glutâmico & - & - & - & 18,3 & 20,9 & 22,1 & 20,7 & 23,6 & 23,3 \\
\hline Glicina & - & - & - & 3,7 & 3,6 & 3,6 & 3,4 & 3,8 & 3,9 \\
\hline Prolina & - & - & - & 8,3 & 7,5 & 7,9 & 7,6 & 8,0 & 8,7 \\
\hline Serina & - & - & - & 5,3 & 4,8 & 5,2 & 5,0 & 5,5 & 5,0 \\
\hline
\end{tabular}

${ }^{1}$ Aminoácidos essenciais. 
18,3 a $23,6 \mathrm{~g} / 100 \mathrm{~g}$ de proteína e de 12,8 a $14,7 \mathrm{~g} / 100 \mathrm{~g}$ de proteína, respectivamente. O conjunto desses aminoácidos representa cerca de $40 \%$ do total.

Os aminoácidos presentes em menores quantidades foram a metionina $(1,2 \%-1,4 \%)$ e o triptofano $(1,5-1,7 \%)$.

Os teores de aminoácidos essenciais (AAE) das cultivares de soja avaliadas neste estudo (Tabela 3 , Fig. 1) foram superiores aos da proteína padrão recomendada pela FAO (1985) para crianças de 2 a 5 anos $(33,9 \mathrm{~g} / 100 \mathrm{~g}$ de proteína). Resultados similares foram obtidos por Eldridge (1983), Zarcadas et al. (1993, 1997) e Vasconcelos et al. (1997).

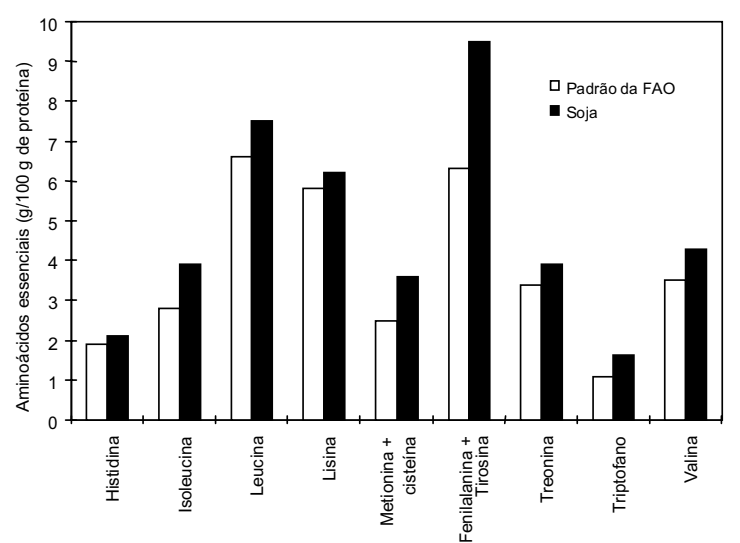

FIG. 1. Comparação da composição média dos aminoácidos essenciais das cultivares estudadas com o padrão da FAO (1985).
De acordo com Erdman \& Fordyce (1989), Young \& Pellett $(1990,1994)$ e Young \& Steinke (1992), a proteína de soja pode satisfazer as necessidades de AAE para crianças e adultos. Esses autores também constataram que, exceto para recém nascidos, é desnecessária a suplementação de metionina sob condições normais de uso de proteína de soja na dieta humana.

A deficiência em metionina detectada na soja e derivados relatadas por outros autores (Costa et al., 1973/74; Ologhobo \& Fetuga, 1984; Mandarino et al., 1992), pode, muito provavelmente, estar relacionada às cultivares estudadas ou aos padrões protéicos recomendados pela FAO (1973), cujos requerimentos de aminoácidos essenciais eram bem maiores que os atuais FAO (1985).

$\mathrm{Na}$ Tabela 4, estão os resultados referentes à composição em ácidos graxos das diferentes cultivares estudadas. A cultivar IAS-5 apresentou maior teor de insaturados, $87,45 \%$, enquanto a Davis, o menor, 83,93\%. A cultivar EMBRAPA-4 apresentou um teor de ácido oléico maior e de linoléico e linolênico bem menores que as demais cultivares estudadas $(39,93 \%, 42,46 \%$ e $4,64 \%$, respectivamente). Sugere-se que estas diferenças sejam devidas à influência tanto da região quanto do ano agrícola. Os demais ácidos graxos estão de acordo com os valores encontrados na literatura quanto a óleo de soja (Pereira et al., 1991).

TABELA 4. Composição em ácidos graxos das cultivares de soja estudadas.

\begin{tabular}{lccccccccc}
\hline \multirow{2}{*}{ Cultivares } & \multicolumn{10}{c}{ Ácidos graxos (\%) } \\
\cline { 2 - 9 } & Mirístico & Palmítico & Palmitoléico & Esteárico & Oléico & Linoléico & Linolênico & Total de & Total de \\
& C14:0 & C16:0 & C16:1 & C18:0 & C18:1 & C18:2 & C18:3 & saturados & insaturados \\
\hline IAS-4 & 0,06 & 9,40 & 0,14 & 3,82 & 21,15 & 57,19 & 7,51 & 13,28 & 85,99 \\
EMBRAPA-4 & 0,03 & 9,27 & 0,14 & 2,87 & 39,93 & 42,46 & 4,64 & 12,17 & 87,17 \\
Davis & 0,08 & 11,84 & 0,06 & 3,39 & 24,87 & 53,08 & 5,92 & 15,31 & 83,93 \\
BR-16 & 0,07 & 10,49 & 0,06 & 4,52 & 23,56 & 53,57 & 6,84 & 15,08 & 84,03 \\
Iguaçu & 0,04 & 9,62 & 0,04 & 3,87 & 22,38 & 56,54 & 6,65 & 13,53 & 85,61 \\
IAS-5 & 0,07 & 8,06 & 0,12 & 3,65 & 24,17 & 55,47 & 7,69 & 11,78 & 87,45 \\
\hline
\end{tabular}




\section{CONCLUSÕES}

1. Todas as cultivares estudadas apresentam composição centesimal típica de soja comercial, com um conteúdo médio, na base seca, de $39,52 \%$ de proteína, $23,04 \%$ de óleo, $5,41 \%$ de cinzas, $5,75 \%$ de fibra e $32,01 \%$ de glicídios totais.

2. O potássio, mineral importante para o equilíbrio eletrolítico dos tecidos, está presente em altíssima quantidade em todas as cultivares avaliadas.

3. A cultivar EMBRAPA-4 apresenta composição em ácidos graxos atípica de soja, com um teor de ácido oléico superior às demais cultivares (39,93\%), e de ácido linoléico e linolênico bem menores $(42,46 \%$ e $4,64 \%$, respectivamente).

4. As seis cultivares estudadas apresentam excelente balanço de aminoácidos essenciais, e podem ser consideradas como uma fonte de proteína de alta qualidade para a alimentação humana.

\section{AGRADECIMENTOS}

À equipe da Área de Tecnologia de Óleos Vegetais e da Área de Controle de Qualidade de Alimento da Embrapa-CTAA, pela realização das análises de ácidos graxos, aminoácidos e minerais.

\section{REFERÊNCIAS}

AGROANALYSIS. Rio de Janeiro: FGV, v.16, n.4, 1996 $52 \mathrm{p}$.

AMARAL, A. Alimentação Racional. In : MIYASAKA, S.; MEDINA, J.C. (Eds.). A soja no Brasil. Campinas, SP. ITAL, 1981. p.832-839.

ASSOCIATION OF OFFICIAL ANALYTICAL CHEMISTS (Arlington, VA). Official methods of analysis. 14.ed. Washington, DC, 1984. 1141p.

COSTA, S.I.; MIYA, E.E.; FUJITA, J.T. Composição química e qualidades organolépticas e nutricionais das principais variedades de soja cultivadas no Estado de São Paulo. Coletânea do Instituto de Tecnologia de Alimentos, Campinas, v.5, p.305$319,1973 / 74$.

ELDRIDGE, A.C. Chemical comparison of Mexican soybean variety with a US variety. Journal of the
American Oil Chemists' Society, Champaign, v.60, n.6, p.1132-1134, June 1983.

ERDMAN, J.W.; FORDYCE, E.J. Soy products and the human diet. American Journal of Clinical Nutrition, v.49, p.725-737, 1989.

FAO (Roma, Italy). Energy and Protein Requeriments Roma: FAO/WHO, 1973. 118p. (FAO Nutrition Meetings Report Series 52, and WHO Technical Report Series, 522).

FAO (Geneva, Italy). Energy and Protein Requeriments. Geneva: FAO/WHO, 1985. (FAO Nutrition Meetings Report Series 724, and WHO Technical Report Series, 724).

HARTMAN, L.; LAGO, R.C.A. Rapid preparation of fatty acid methyl esters from lipids. Laboratory Practice, London, v.22, n.8, p.175-176, 1973.

HORAN, F.E. Soy protein products and their production. Journal of the American Oil Chemists' Society, Champaign, v.51, n.1, p.67a-73a, Jan. 1974.

INSTITUTO ADOLFO LUTZ (Campinas, SP). Normas analíticas do Instituto Adolfo Lutz. 3.ed. São Paulo, 1985. v.1, 371p.

JAFFE, G. Phytic acid in soybeans. Journal of the American Oil Chemists' Society, Champaign, v.58, n.3, p.493-495, 1981.

LIENER, I.E. Factors affecting the nutritional quality of soya products. Journal of the American Oil Chemists' Society, Champaign, v.58, p.406-415, 1981.

LIU, K.; ORTHOEFER, F.; THOMPSON, K. The case for food-grade soybean varieties. INFORM, International News on Fats Oils and Related Materials, Champaign, v.6, n.5, p.593-599, May 1995.

LÓPEZ-ANDREU, F.J.; ARCE, A.; ESTEBAN, R.M.; ZORNOZA, P. Composición química y calidad de semillas de soja españolas. Fracción lipídica, mineral y proteínica. Grasas y Aceites, Sevilla, v.36, n.2, p.93-97, mar./abr. 1985.

MANDARINO, J.M.G.; CARRÃO-PANIZZI, M.C.; OLIVEIRA, M.C.N. Chemical composition of soybean seed from different production areas of Brazil. Arquivos de Biologia e Tecnologia, Curitiba, v.35, n.4, p.647-653, dez. 1992.

MOHAMED, A.I.; MEBRAHTU, T.; RANGAPPA, M. Nutrient composition and anti-nutritional factors in 
selected vegetable soybean (Glycine max [L.] Merr.). Plant Foods for Human Nutrition, Netherlands, v.41, p.89-100, 1991.

OLIVEIRA, J.E.D. de. Valor da soja como alimento. In: MIYASAKA, S.; MEDINA, J.C. (Eds.). A soja no Brasil. Campinas, SP: ITAL, 1981. p.820-823.

OLOGHoBo, A.D.; FetUGA, B.L. Biochemical assessment of some new varieties of soybeans. Food Chemistry, Barking, v.13, n.2, p.103-115, 1984.

PEREIRA, D.A.; JABLONKA, F.H.; SZPIZ, R.R.; LAGO, R.C.A.; CABRAL, L.C. Study of twenty principal soybean varieties cultivated in Brazil with respect to quantity and quality of oil. In: INTERNATIONAL MEETING ON FATS OILS TECHNOLOGY, 1991, Campinas. Proceedings... Campinas: UNICAMP/GTZ, 1991. p.147-149.

SAKLA, A.B.; GHALI, Y.; EL-FARRA, A.; RIZK, L.F. The effect of environmental conditions on the chemical composition of soybean seeds: deactivation of trypsin inhibitor and effect of microwave on some components of soybean seeds. Food Chemistry, Barking, v.29, n.4, p.269-274, Apr. 1988.

SMITH, A.K.; CIRCLE, S.J. Chemical composition of the seed. In: SMITH, A.K.; CIRCLE, S.J. (Eds.). Soybeans: Chemistry and technology. Westport: The AVI Publishing, 1972. v.1, ch.3, p.61-92.

TANGO, J.S.; TURATTI, J.M.; SILVA, M.T.C.; SHIROSE, I.; YOTSUYANAGI, K. Influência do local de plantio no teor e características do óleo de algumas cultivares de soja. Boletim do Instituto de Tecnologia de Alimentos, Campinas, v.20, n.4, p.355-374, out./dez. 1983.

TURATTI, J.M.; SALLES, A.M.; SANTOS, L.C. dos; MORI, E.E.M.; FIGUEIREDO, I.B. Estudos preliminares com cultivares de soja para produção de leite. Boletim do Instituto de Tecnologia de Alimentos, Campinas, v.16, n.3, p.289-305, jul./set. 1979.

VASCONCELOS, I.M.; SIEBRA, E.A.; MAIA, A.A.B.; MOREIRA, R.A.; NETO, A.F.; CAMPELO, G.J.A.; OLIVEIRA, J.T.A. Composition, toxic and antinutritional factors of newly developed cultivars of Brazilian soybean (Glycine max). Journal of the Science of Food Agriculture, New Jersey, v.75, n.4, p.419-426, Dec. 1997.

YOUNG, V.R.; PELLETT, P.L. Plant proteins in relation to human protein and amino acid nutrition. American Journal Clinical and Nutrition, New York, v.59, n.5(s), p.1203s-1212s, 1994.

YOUNG, V.R.; PELLETT, P.L. Protein evaluation, amino acid scoring and the food and drug administration's proposed food labeling regulations. The Journal of Nutrition, Davis, v.121, n.1, p.145-150, Jan. 1990.

YOUNG, V.R.; STEINKE, F.H. Protein and amino acid requirements in relation to dietary food protein needs. In: STEINKE, F.H.; WAGGLE, D.H.; VOLGAREV, M.N. (Eds.). News protein food in human health: Nutrition, prevention and therapy. Boca Raton, FL: CRC, 1992. p.9-31.

ZARCADAS, C.G.; YU, Z.; VOLDENG, H.D.; MINERO-AMADOR, A. Assessment of the protein quality of a new high-protein soybean cultivar by amino acid analysis. Journal of Agricultural and Food Chemistry, Washington, DC, v.41, n.4, p.641643, Apr. 1993.

ZARCADAS, C.G.; VOLDENG, H.D.; YU, Z.; SHANG, K.; PATTISON, P.L. Comparision of the protein quality of five new northern adapted natto soybean cultivars by amino acid analysis. Journal of Agricultural and Food Chemistry, Washington, DC, v.45, n.6, p.2013-2019, June 1997. 